\title{
Poor State, Rich State: Understanding the Variability of Poverty Rates across U.S. States
}

\author{
Jennifer Laird, ${ }^{a}$ Zachary Parolin, Jane Waldfogel, ${ }^{\mathrm{c}}$ Christopher Wimer ${ }^{\mathrm{c}}$
}

a) Lehman College; b) University of Antwerp; c) Columbia University

Abstract: According to the Supplemental Poverty Measure, state-level poverty rates range from a low of less than 10 percent in lowa to a high of more than 20 percent in California. We seek to account for these differences using a theoretical framework proposed by Brady, Finnigan, and Hübgen (2017), which emphasizes the prevalence of poverty risk factors as well as poverty penalties associated with each risk factor. We estimate state-specific penalties and prevalences associated with single motherhood, low education, young households, and joblessness. We also consider state variation in the poverty risks associated with living in a black household and a Hispanic immigrant household. Brady et al. (2017) find that country-level differences in poverty rates are more closely tied to penalties than prevalences. Using data from the Current Population Survey, we find that the opposite is true for state-level differences in poverty rates. Although we find that state poverty differences are closely tied to the prevalence of high-risk populations, our results do not suggest that state-level antipoverty policy should be solely focused on changing "risky" behavior. Based on our findings, we conclude that state policies should take into account cost-of-living penalties as well as the state-specific relationship between poverty, prevalences, and penalties.

Keywords: poverty; policy; inequality

Citation: Laird, Jennifer, Zachary Parolin, Jane Waldfogel, and Christopher Wimer. 2018. "Poor State, Rich State: Understanding the Variability of Poverty Rates across U.S. States." Sociological Science 5: 628-652.

Received: June 27, 2018

Accepted: August 21, 2018

Published: October 3, 2018

Editor(s): Jesper Sørensen, Olav Sorenson

DOI: $10.15195 / \mathrm{v} 5 . \mathrm{a} 26$

Copyright: (C) 2018 The Author(s). This open-access article has been published under a Creative Commons Attribution License, which allows unrestricted use, distribution and reproduction, in any form, as long as the original author and source have been credited. (C)(i)
DOVERTY rates vary considerably in the United States. According to the best available measure, the Supplemental Poverty Measure (SPM), state-level poverty rates vary from a low of less than 10 percent in Iowa to a high of more than 20 percent in California (Renwick and Fox 2016). We investigate two potential reasons for disparities in state-level poverty rates. First, we consider the demographic composition of the population. Depending on their demographic characteristics, some households are more likely than others to experience poverty. Second, we examine whether the relationship between demography and poverty varies across states. According to the demographic composition hypothesis, high-poverty states will have a high prevalence of high-risk households. If poverty rates vary across states because the relationship between demography and the probability of living in poverty varies across states, high-poverty states will have a high probability of poverty for high-risk households. In this analysis, we investigate these differences in an effort to account for variation in poverty rates across U.S. states.

Drawing from a theoretical framework designed by Brady, Finnigan, and Hübgen (2017) in their study of poverty rates across countries, this study compares the prevalence of, and the penalty to, household characteristics that have been associated with an increased risk of poverty. Consistent with Brady et al. (hereafter $\mathrm{BFH}$ ), we focus on low education, single motherhood, early household formation, and unemployment. Given well-established racial and ethnic disparities in U.S. economic outcomes, we also consider the distribution of state populations and 
state-specific poverty penalties associated with being black and being foreign-born Hispanic. Prevalence is defined as the share of the population with a given risk; penalty is defined as the increase in the probability of poverty associated with a given risk.

Using country-level data from the Luxembourg Income Study (LIS), BFH find that unemployment has the largest penalty, followed by low education and young headship. Although single motherhood has been the focus of much of the research on poverty, BFH report that it has the smallest penalty of the four. In many countries, the penalties associated with a given risk are not significant. Compared to other countries, most of which have lower poverty rates, the United States has both a high penalty and a low prevalence associated with each of the four risks. BFH find that welfare generosity significantly moderates the penalty for unemployment and low education. What the BFH study does not address is the extent to which these findings hold within the United States.

BFH's results suggest that compared to other rich democracies, the United States is less effective at using public policy to reduce poverty. What we investigate is whether some states are more effective than others at using policy to reduce poverty. As the federal government rolls back safety net programs (Edin and Shaefer 2015), it will be increasingly up to the states to determine whether and how to implement state-level antipoverty policies. Some states currently offer generous antipoverty programs to enhance what is provided by the federal government; others states impose significant restrictions. In 2015, per capita spending on state and local welfare benefits varied from a low of $\$ 1,135$ in Utah to a high of $\$ 3,110$ in New York State (Urban Institute 2018a). Coverage and benefits for Medicaid, the Earned Income Tax Credit (EITC), the Supplemental Nutrition Assistance Program (SNAP), and Temporary Assistance for Needy Families (TANF) vary widely across states (Nolan et al. 2017; Sommers and Oellerich 2013).

Alternatively, it may be that the uneven distribution of high-risk families is more consequential for explaining variation in poverty rates within the United States. Before we investigate the prevalences-versus-penalties question, we first show how widely SPM poverty rates vary across states. Second, we quantify state-specific prevalences and penalties associated with each poverty risk. Third, we show the extent to which government taxes and transfers reduce penalties. We then attempt to fully explain poverty differences between states using the prevalence-penalty framework. Contrary to what BFH find in their cross-country analysis, our results indicate relatively little variation in penalties across states for most risk factors both before and after taxes and transfers. After controlling for risk factor prevalences, penalties, and variation in the cost of living across states, between-state variation in the probability of living in poverty decreased by 92 percent. Finally, for each of the 50 states, we decompose the difference between the state's poverty rate and the poverty rate for the rest of the nation into the part that is due to differences in penalties and the part that is due to differences in prevalences. Foreshadowing our results, we find that the contribution of prevalences and penalties to state-level poverty varies substantially across states.

Unlike most sociological studies of poverty, we use the Supplemental Poverty Measure (SPM) rather than the Official Poverty Measure (OPM). The SPM is superior 
to the OPM in that the SPM is adjusted for cost-of-living differences between metropolitan areas, and the SPM includes government transfers and taxes in the calculation of household resources.

\section{Theoretical Framework}

The premise of BFH's prevalence-penalty framework is that poverty is a function of the following: (1) whether or not you live in a high-risk household and (2) how those risks interact with the effects of where you live. At the state level, the poverty rate depends on the prevalence of high-risk households and the penalties attached to each poverty risk. BFH define poverty risks as individual labor market and family characteristics that are more common among the poor than the nonpoor.

Of the four major risks BFH identify (low education, single motherhood, young headship, and unemployment), single motherhood has arguably received the most attention in the poverty literature. Compared to households with two parents, the poverty rate for single-parent, female-headed households is substantially higher in the United States as well as in many European countries (McLanahan 2004). In their analysis of marriage patterns across U.S. states, Kickham and Ford (2009) find that the prevalence of divorce is strongly associated with childhood poverty.

Independent of the association with single motherhood, young adulthood in general and early family formation in particular significantly increase the odds of living in poverty. Early marriage and early childbearing both have effects on a household's poverty status, in part through diminished educational prospects. Teen pregnancy significantly reduces the likelihood of high school graduation (Diaz and Fiel 2016). Dahl (2010) finds that marrying before the age of 16 increases a woman's probability of living in poverty when she is older by 31 percentage points. Young adults in general are much more likely to enter poverty than those in other stages of life (Cellini, McKernan, and Ratcliffe 2008).

Educational attainment decreases the odds of living in poverty in part because education decreases the odds of early family formation, single motherhood, and employment instability. Women with higher education have fewer children, and they are more likely than their less educated counterparts to have children after marrying (Cohen 2015). Education affects the expected wage rate and the resources available to pay for child care (Harris 1996). In her study of census data from 1960 to 2000, McLanahan (2004) finds that although employment increased for all mothers during that time period, the increase was the greatest for the most educated mothers.

Unlike the other three risk factors, employment is highly cyclical. Yet at any point in the business cycle, unemployment will be higher among lower-wage workers (Blank et al. 1993). Using the Survey of Income and Program Participation, McKernan and Ratcliffe (2005) find that the likelihood of falling into poverty increases by 11 percentage points if a household head experiences a loss of employment and 5 percentage points if a spouse or other household member loses employment.

States can reduce poverty both by preventing the occurrence of risk factors (minimizing risk prevalence) and by minimizing poverty penalties associated with 
each risk factor. States can aim to reduce risk prevalence by promoting education, marriage, delayed childbearing, or employment. The likelihood of early family formation can be reduced through the expansion of Medicaid coverage for family planning services (Yang and Gaydos 2010). States can improve high school and college outcomes by offering multiple diploma paths to graduation, allowing undocumented high school students to qualify for in-state tuition policies, offering guaranteed admission to qualified community college students, developing college readiness programs in high schools, and expanding financial aid (Flores 2010; Perna et al. 2008). State welfare transfers should affect penalties by reducing the likelihood that high-risk households will fall into poverty. To the extent that the U.S. welfare system is focused on helping adults with dependent children (Currie 2006; Hardy, Smeeding, and Ziliak 2018) and given that, historically, single-mother families have been the primary recipient of welfare transfers (Moffitt 2015), we expect transfers to have the largest impact on penalties for single motherhood.

Interstate variation in penalties will be constrained by two factors: (1) the availability of U.S. safety net programs in all 50 states and (2) the small contribution of state transfers to total welfare spending. Following the Personal Responsibility and Work Opportunity Reconciliation Act of 1996 (PRWORA), Aid to Families with Dependent Children (AFDC) - the primary cash assistance program for low-income families-was replaced with Temporary Assistance for Needy Families (TANF), a fixed block grant. Both the savings and the extra costs of TANF accrue to the states. As a result, direct cash assistance has been rolled back, and noncash benefits (i.e., food stamps and refundable tax credits) have become a major component of the safety net. In the decades following PRWORA, the proportion of state TANF budgets allocated for welfare cash assistance declined from an average of 70 percent to only 23 percent (Center on Budget and Policy Priorities 2015a; Parolin and Luigjes 2018). State General Assistance (GA) programs, which are funded entirely by states and are intended for low-income households that are not eligible for other public assistance programs, have become increasingly rare. Since the 1980s, most states have either cut back or eliminated their GA programs (Center on Budget and Policy Priorities 2015b). According to Current Population Survey (CPS) data, state welfare transfers represent 1 percent of mean disposable household income, whereas federal welfare transfers represent 23 percent.

And yet, states are social policy laboratories. States vary with respect to the distribution of resources, the regulation of risks, and the allocation of opportunities (Brady 2009). State versions of the Earned Income Tax Credit (EITC), which currently exist in about half of U.S. states, vary substantially with respect to coverage and generosity. Prior research suggests that the EITC has a particularly strong antipoverty effect on single mothers with low levels of income and education. Hoynes and Patel (2017) report that single filers with children account for nearly 60 percent of EITC filers and almost 75 percent of the cost of the credit. The EITC encourages labor force participation among single mothers because (1) the benefit is only available to taxpayers with earned income, (2) the benefit amount increases as income increases for those at the bottom of the income distribution (the "phase-in" range), and (3) the size of the benefit is substantially larger for those with qualifying children. Hoynes and Patel (2017) find that for families headed by single women 
without college degrees, a policy-induced $\$ 1,000$ increase in the EITC leads to an 8.4 percentage point reduction in the share of those living below the poverty level.

States also vary with respect to coverage and eligibility rules for the Supplemental Nutrition Assistance Program (SNAP, formerly food stamps). SNAP income tests, asset limits, and work requirements all vary by state. During the period of our study (2011-2015), SNAP participation for people below the SPM poverty line ranged from a low of 47 percent in Wyoming to a high of 73 percent in Illinois. ${ }^{1}$ Access to SNAP can be particularly important for the unemployed. Historically, SNAP enrollment has expanded when the economy is weak and contracted when the economy improves (Bitler and Hoynes 2016). In this way, SNAP reduces the likelihood of falling into poverty during temporary periods of unemployment (Center on Budget and Policy Priorities 2018).

Cash assistance through TANF-a relatively small component of the safety net that has shrunk over time-varies substantially by state. Some states have adopted policies to discourage TANF participation-policies such as fingerprinting, drug-testing, and increasing the frequency of recertification requirements-whereas others have not (Urban Institute 2018b). Nolan et al. (2017) estimate that states range from covering as little as 8 percent of their TANF-eligible population in Idaho to as much as 70 percent of the eligible population in Maine. States also differ with respect to the share of TANF funds that are spent on cash assistance (versus noncash assistance, such as work training, pregnancy prevention, and child care services). In 2014, the share of TANF funds spent on cash assistance varied from a low of 6 percent in Illinois to a high of 61 percent in South Dakota (Schott, Pavetti, and Floyd 2015).

In addition to EITC, SNAP, and TANF, states also vary with respect to Medicaid coverage. During the time period of our study (2011-2015), 30 states expanded Medicaid eligibility using federal funds provided through the Patient Protection and Affordable Care Act. In the states that expanded Medicaid eligibility, according to the Centers for Medicare and Medicaid Services, Medicaid enrollment increased by more than 38 percent. As of 2014, women and children made up 80 percent of the Medicaid population. Prior research suggests that Medicaid has a significant antipoverty effect, particularly for women and children. Using data from the 2011 Current Population Survey, Sommers and Oellerich (2013) estimate that by reducing out-of-pocket medical spending, Medicaid kept at least 2.6 million Americans out of poverty, reducing the SPM poverty rate by 0.8 percentage points for women and 1 percentage point for children, which is equivalent to the combined impact of TANF, WIC, school lunches, and energy assistance.

According to $\mathrm{BFH}$, poverty risks cannot be ascriptive and must be at least partially malleable (i.e., characteristics that can theoretically change in response to policy interventions). Because of this theoretical constraint and the challenges related to measuring race across countries, race and ethnicity are not included in BFH's cross-national theoretical framework. In their supplementary analyses, BFH find that blacks and Latinos have higher penalties than non-Hispanic whites in the United States. BFH conclude that "racial disadvantage appears to augment the penalties for risk and contributes to the United States having unusually high penalties." In addition to being less likely to be born into wealthy households and 
more likely to experience downward economic mobility, African Americans are also concentrated in states that have less generous welfare policies (Bloome 2014; Chetty et al. 2018; Hahn et al. 2017). Despite paying taxes and having higher employment rates relative to similarly educated native-born individuals, Hispanic immigrants have higher poverty rates in part because many of them are not eligible for safety net programs (Laird 2015; Lopez and Cohn 2011). Some states offer programs for immigrants who are not eligible for federal programs, whereas others do not.

We operationalize these racial and ethnic disadvantages as two additional risk factors in the prevalence-penalty framework: living in a household with a black head of household and living in a household with a foreign-born Hispanic head of household. We measure how states penalize black and foreign-born Hispanic households above and beyond the penalties associated with the other four risk factors.

As a first step toward understanding how state-level poverty is shaped by risk prevalences and penalties, we measure the prevalences and penalties associated with each risk factor at the state level. We then show the extent to which taxes and transfers reduce the penalties associated with each of the four risk factors. To see how prevalences and penalties affect between-state variation in the probability of living in poverty, we estimate the variance in state random effects before and after controlling for prevalences and penalties. The final step of the analysis quantifies the contribution of prevalences and penalties to the deviation of each state from the poverty rate for the rest of the country.

\section{Data and Methods}

We use data from the 2012-2016 Current Population Survey Annual Social and Economic Supplement (CPS ASEC), a survey that is sponsored jointly by the U.S. Census Bureau and the U.S. Bureau of Labor Statistics. The CPS ASEC is the source for U.S. government poverty and labor market statistics. Studies comparing SNAP and TANF reporting in the CPS to administrative records have found that in the CPS, at least 40 percent of SNAP recipients and at least 60 percent of TANF recipients do not report benefit receipt (Fox et al. 2017; Meyer and Mittag 2015). We use the Urban Institute's Transfer Income Model (TRIM), which simulates actual program rules in each year to correct for the underreporting of transfer program benefits in the CPS. ${ }^{2}$ The most recent TRIM files are for the 2016 CPS (2015 calendar year). The sample size across all five years is 788,237 .

Our measure of poverty is based on the Supplemental Poverty Measure (SPM). In addition to after-tax income, SPM resources include in-kind benefits-the Supplemental Nutrition Assistance Program (SNAP); the National School Lunch Program; the Women, Infants, and Children program (WIC); the Housing Assistance Program; and the Low Income Home Energy Assistance Program (LIHEAP)—minus medical out-of-pocket expenses, work-related expenses, and childcare expenses. Our SPM thresholds reflect contemporary purchasing patterns adjusted for the relative living expenses of metropolitan and nonmetropolitan areas within states. ${ }^{3}$ The SPM household includes foster children and cohabiters and their children (all SPM household members have the same resources). More details on the computation of 
the SPM can be found in annual U.S. Census Bureau SPM reports (e.g., Short 2015). Similar to Brady et al. (2017), we restrict our sample to individuals in households with heads under the age of 65.

Our definitions of young headship, single motherhood, low education, and unemployment are consistent with BFH. We assign the young headship risk to those living in a household that is headed by someone less than 25 years of age. ${ }^{4}$ In addition to capturing early household formation, this measure also disproportionately includes those who are living alone and cohabiters. A single mother-headed household is one without a cohabiting couple that is headed by an unmarried woman. Single mother-headed households have a least one child under the age of 18. A low education household is one in which the head does not have a high school diploma. ${ }^{5}$ An unemployed household is one in which there are no employed individuals at the time of the survey. To capture the effects of race and ethnic disadvantages associated with poverty, we use dummy variables to identify whether or not individuals live in a household with a black head and whether or not individuals live in a household with a foreign-born Hispanic head.

Our definition of household is based on the SPM definition of a poverty unit (Renwick and Fox 2016). In addition to family members (i.e., all individuals in the household related by blood, marriage, or adoption), the SPM unit includes foster children under the age of 22, unrelated children under the age of 15 , unmarried partners, and family members of unmarried partners. We identify the head of the SPM unit as the household reference person identified by the U.S. Census Bureau. For those secondary SPM units without a household reference person (e.g., unrelated subfamilies), we identify the head as the oldest member of the unit. ${ }^{6}$

Consistent with $\mathrm{BFH}$, we use a multilevel linear probability model to estimate the probability of living below the poverty threshold for individual $i$ in state $j$ :

$$
Y_{i}=\alpha_{j[i]}+\beta_{j[i]} X_{i}+\epsilon_{i}
$$

where $\alpha_{j}$ are the intercepts for each state, and $\mathbf{X}_{i}$ is the matrix of explanatory variables. ${ }^{7}$ The baseline model is a random-intercept model with no controls. To determine how the probability of living in poverty varies after controlling for the prevalence of risk factors, we add individual and household characteristics to the baseline model, including the household risks factors. We then estimate the penalties associated with each risk for each state by allowing the $\beta$ for each risk factor to vary across states. The models include year fixed effects as well as a control metropolitan and/or nonmetropolitan status.

We measure the importance of prevalences and penalties for each state by estimating a Blinder-Oaxaca decomposition (Binder 1973; Oaxaca 1973). ${ }^{8}$ We decompose the difference in the SPM poverty probability between state $j$ and the rest of the country $z$ into the part that is due to differences in penalties and the part that is due to differences in prevalences:

$$
\bar{Y}_{j}-\bar{Y}_{z}=\underbrace{\left(\bar{X}_{j}-\bar{X}_{z}\right) \beta_{z}}_{\text {prevalences }}+\underbrace{\bar{X}_{z}\left(\beta_{j}-\beta_{z}\right)}_{\text {penalties }}+\underbrace{\left(\bar{X}_{j}-\bar{X}_{z}\right)\left(\beta_{j}-\beta_{z}\right)}_{\text {interaction }} .
$$


The interaction term accounts for the fact that cross-group differences in explanatory variables and coefficients can occur at the same time.

SPM poverty, our dependent variable of interest, includes adjustments for geographical differences in expenses and the cost of housing. ${ }^{9}$ This adjustment is important because the resources needed for the consumption of basic needs will vary between and within states depending on the cost of living. In the online supplement, we include all of our results without the geographic adjustment to the SPM poverty threshold.

\section{Results}

We first provide a descriptive illustration of how the poverty rate, defined using the Supplemental Poverty Measure (SPM), varies across states (Figure 1).

California has the highest poverty rate, with one in five residents living below the SPM threshold. Iowa has the lowest poverty rate (7.3 percent). In their recent study disaggregating SPM trends by state using geographic adjustments, Nolan et al. (2016) report that California is the only state to experience rising poverty rates in recent years. The causes of poverty change over time are beyond the scope of this analysis, but as Wimer et al. $(2015,2017)$ have documented in their reports on the California Poverty Measure, California has an exceptionally high cost of living.

We show the bivariate relationship between poverty rates and the prevalence of the six major risk factors in Figure $2 .{ }^{10}$

The scatterplots in Figure 2 illustrate the variation in risk prevalence ( $x$ axis) relative to the variation in SPM poverty rates (y axis) with fit lines. The risk factor prevalence most highly correlated with state-level poverty rates is the proportion of residents living in a household headed by someone without a high school diploma (correlation $=0.71$ ), followed by the proportion of residents living in a household with a foreign-born Hispanic head (correlation $=0.69$ ). The risk factor that varies most across states is having a black head of household. The risk factor prevalence that is least associated with state-level poverty is the proportion of residents living in a household with a head under the age of 25 (correlation $=0.02$ ).

We estimate penalties by allowing the slope for each risk to vary by state in a model with state random effects. The model includes year fixed effects, a control for the number of people in the household, and a control for metropolitan and/or nonmetropolitan status. Figure 3 shows the bivariate relationship between the slopes (penalties) associated with each risk and state poverty rates.

With the exception of unemployment, risk factor prevalences (Figure 2) are more highly correlated with poverty than are risk factor penalties (Figure 3). ${ }^{11}$ Of the six risk factors, unemployment is the penalty that is most highly correlated with state poverty rates. Having a black head of household is the penalty that is the least correlated with state poverty rates. Having a foreign-born Hispanic head is the penalty with the largest variation across states. The penalty that has the narrowest distribution across states is having a young head of household. In Figures 2 and 3, California (the state with the highest SPM poverty rate) stands out as an outlier in every plot. The SPM poverty rate for California is much higher than what would be expected based on both the poverty penalties California imposes on high-risk 


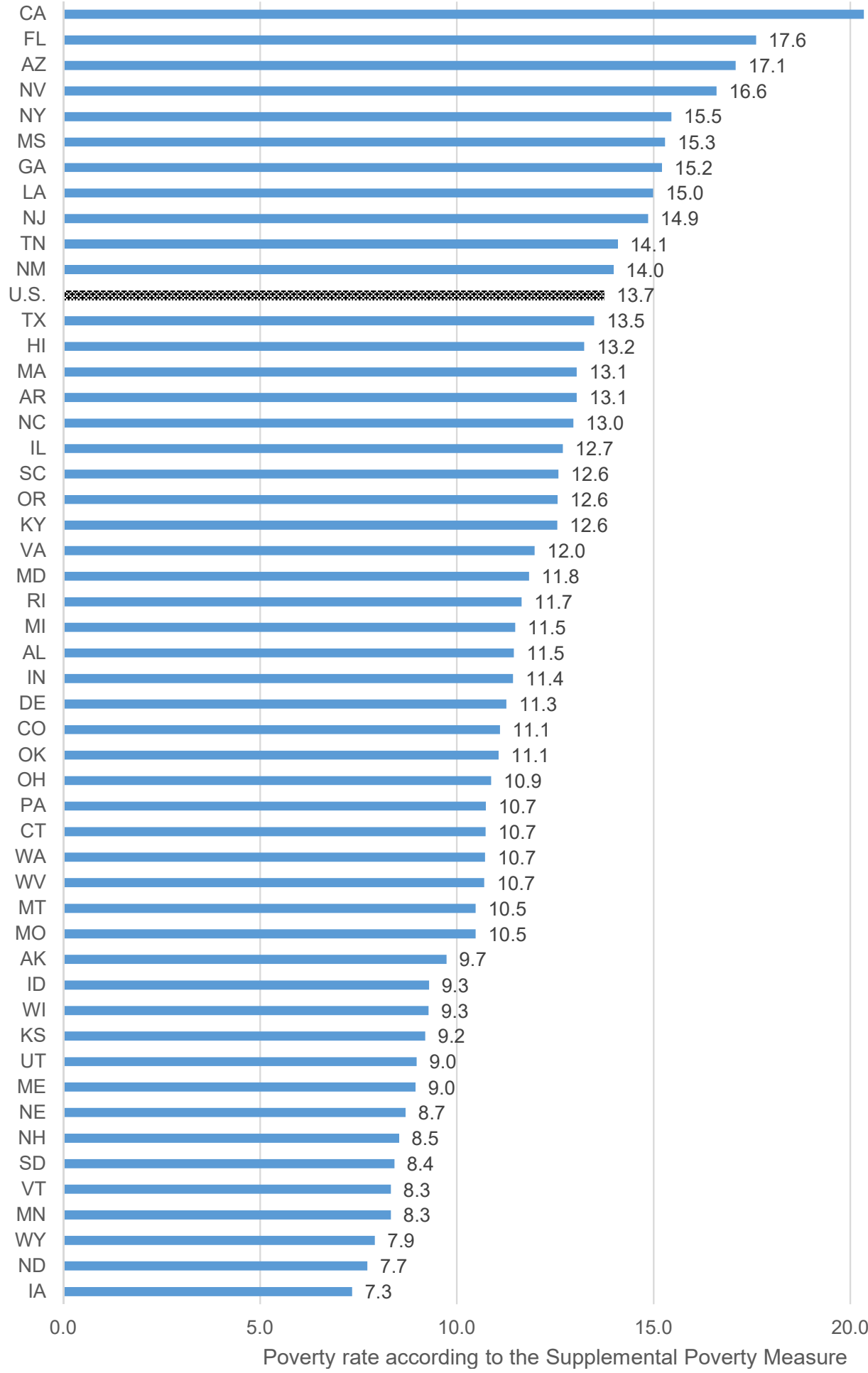

Figure 1: Poverty rates by state according to the SPM, adjusted for SNAP, SSI, and TANF underreporting (2012-2016 CPS). States are indicated by their postal code abbreviations. 

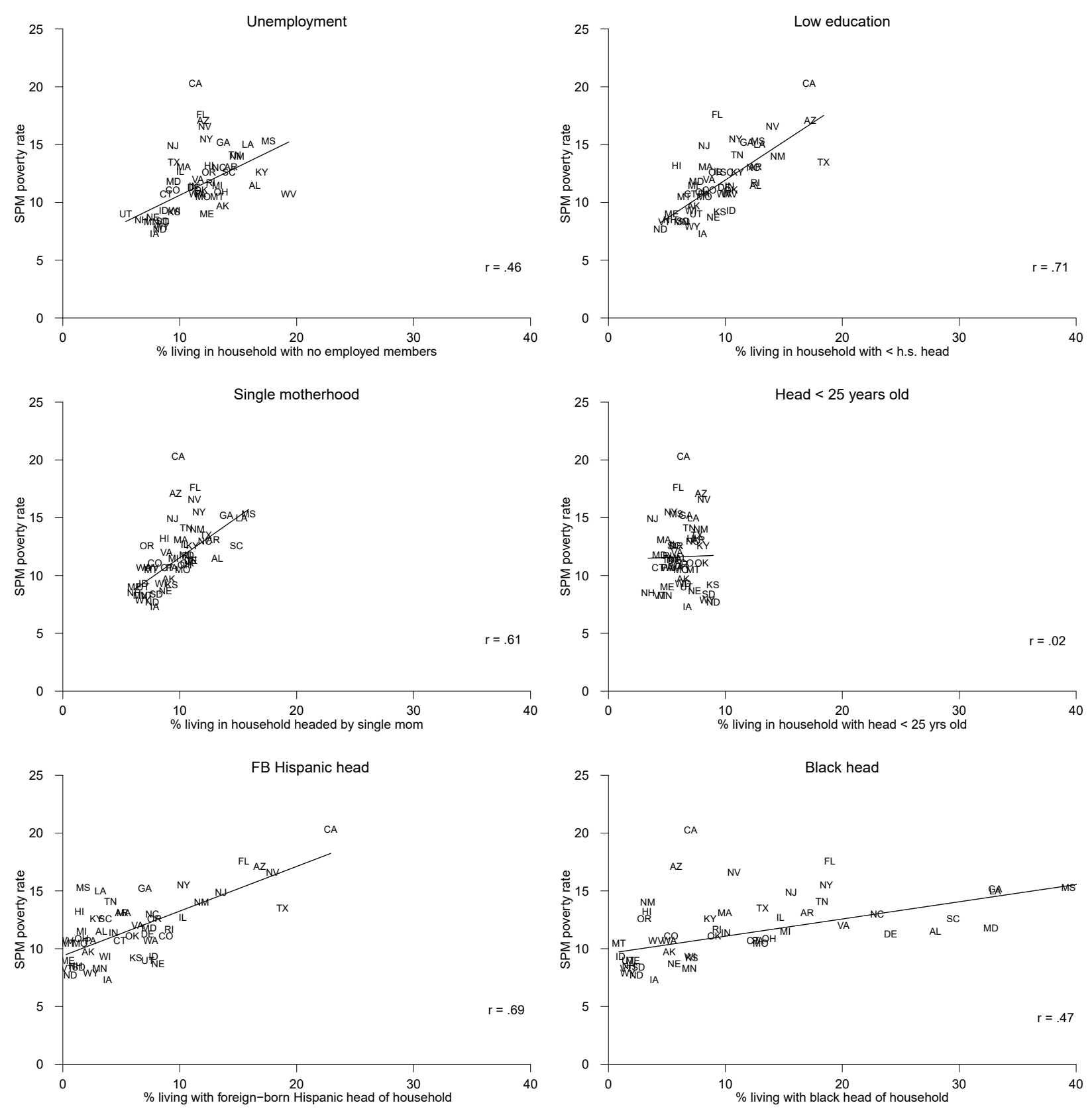

Figure 2: Bivariate relationship between risk prevalences and SPM poverty rates (2012-2016 CPS). Adjustments for SNAP, SSI, and TANF underreporting were made using the Urban Institute Transfer Income Model (TRIM). States are indicated by their postal code abbreviations.

households and the prevalence of high-risk households within California. However, when we remove the adjustment for the cost of housing (see Figures A2-A3 of the online supplement), California is no longer an outlier. 

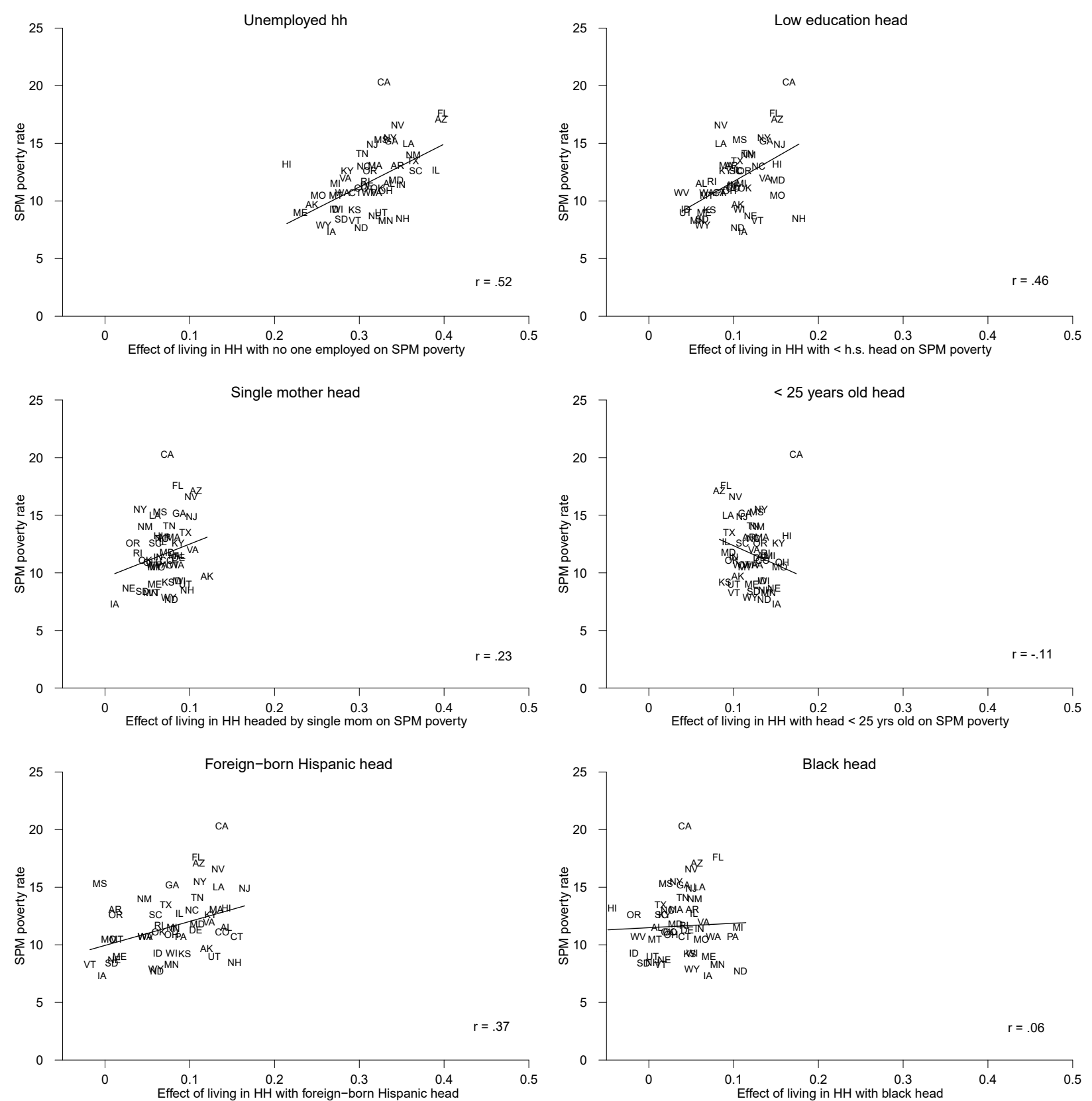

Figure 3: Bivariate relationship between risk penalties and SPM poverty rates (2012-2016 CPS). Adjustments for SNAP, SSI, and TANF underreporting were made using the Urban Institute Transfer Income Model (TRIM). Effects represent coefficients from varying slope linear probability models predicting SPM poverty. The nonvarying slopes in the model are year fixed effects and a control for metropolitan and/or nonmetropolitan status. States are indicated by their postal code abbreviations.

\section{Penalties before and after Taxes and Transfers}

Figures 4 through 9 below show penalties before and after taxes and transfers (vertical lines represent 95 percent confidence intervals). 


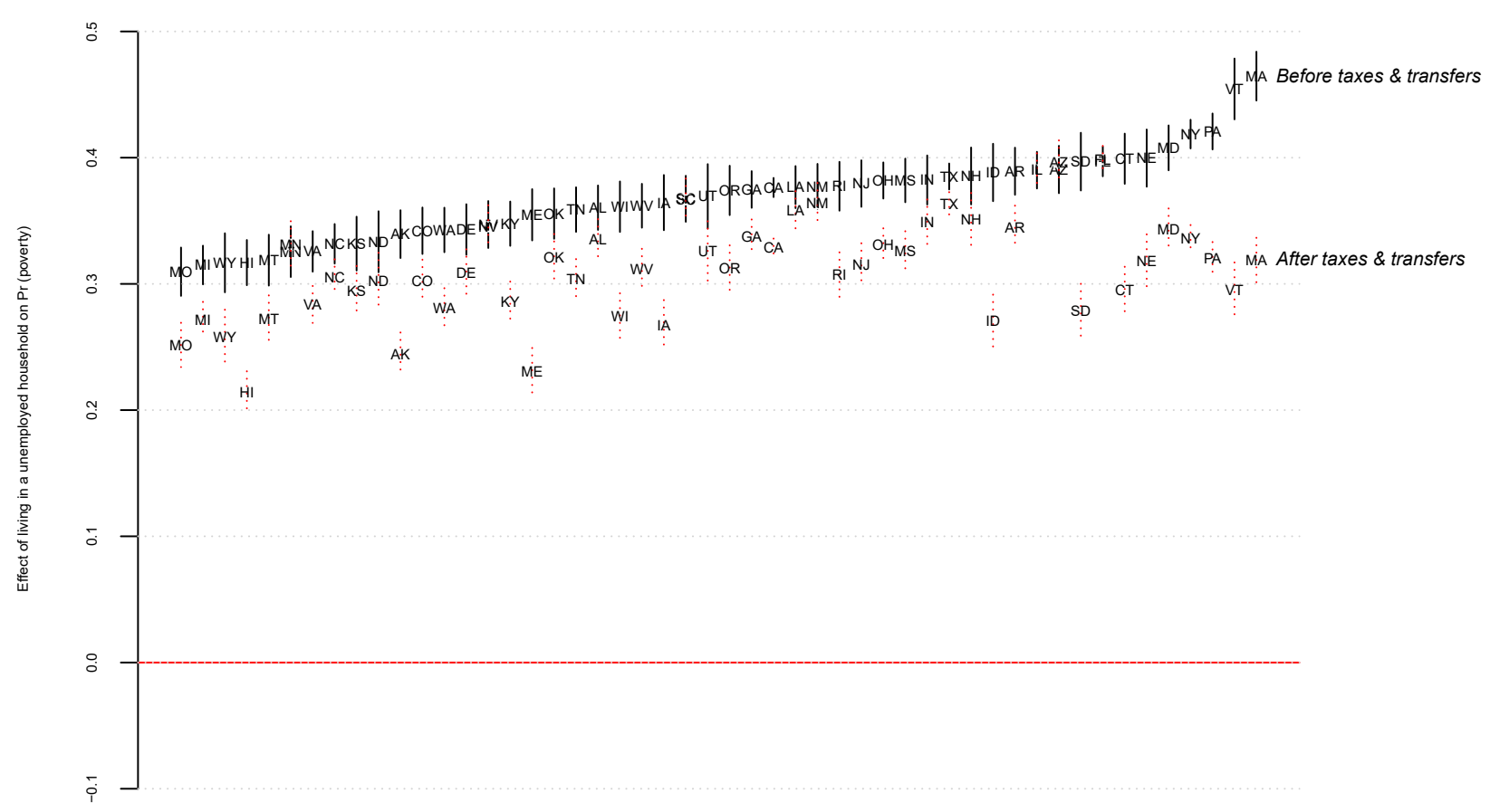

Figure 4: Unemployment penalty: effects of living in an unemployed household on Pr (poverty) before and after taxes and transfers (2012-2016 CPS). Adjustments for SNAP, SSI, and TANF underreporting were made using the Urban Institute Transfer Income Model (TRIM). Effects represent coefficients from varying slope linear probability models predicting SPM poverty. The nonvarying slopes in the model are year fixed effects and a control for metropolitan and/or nonmetropolitan status. States are indicated by their postal code abbreviations.

The penalty-reducing impact of taxes and transfers varies across states. According to the coefficient of variation, penalties vary more after taxes and transfers than before (with the exception of in households with a young head). Transfers have the largest effect on single-mother penalties: The penalties for single-mother households are reduced by an average of 18 percentage points after taking taxes and transfers into account. Taxes and transfers reduce the penalties for low education by an average of 8 percentage points. For unemployment, living in a foreign-born Hispanic household, and living in a black household, the reduction is an average of 5 percentage points. Taxes and transfers reduce the penalty for those with a young head of household by an average of 1 percentage point.

\section{Fully Accounting for Interstate Poverty Differences}

In the analysis that follows, we present interstate differences in poverty depending on whether we include taxes and transfers, risk factor prevalences, and risk factor penalties that are above and beyond what is included taxes and transfers (Figure 10). Taken together, these factors account for 92 percent of the variance in state random effects. 


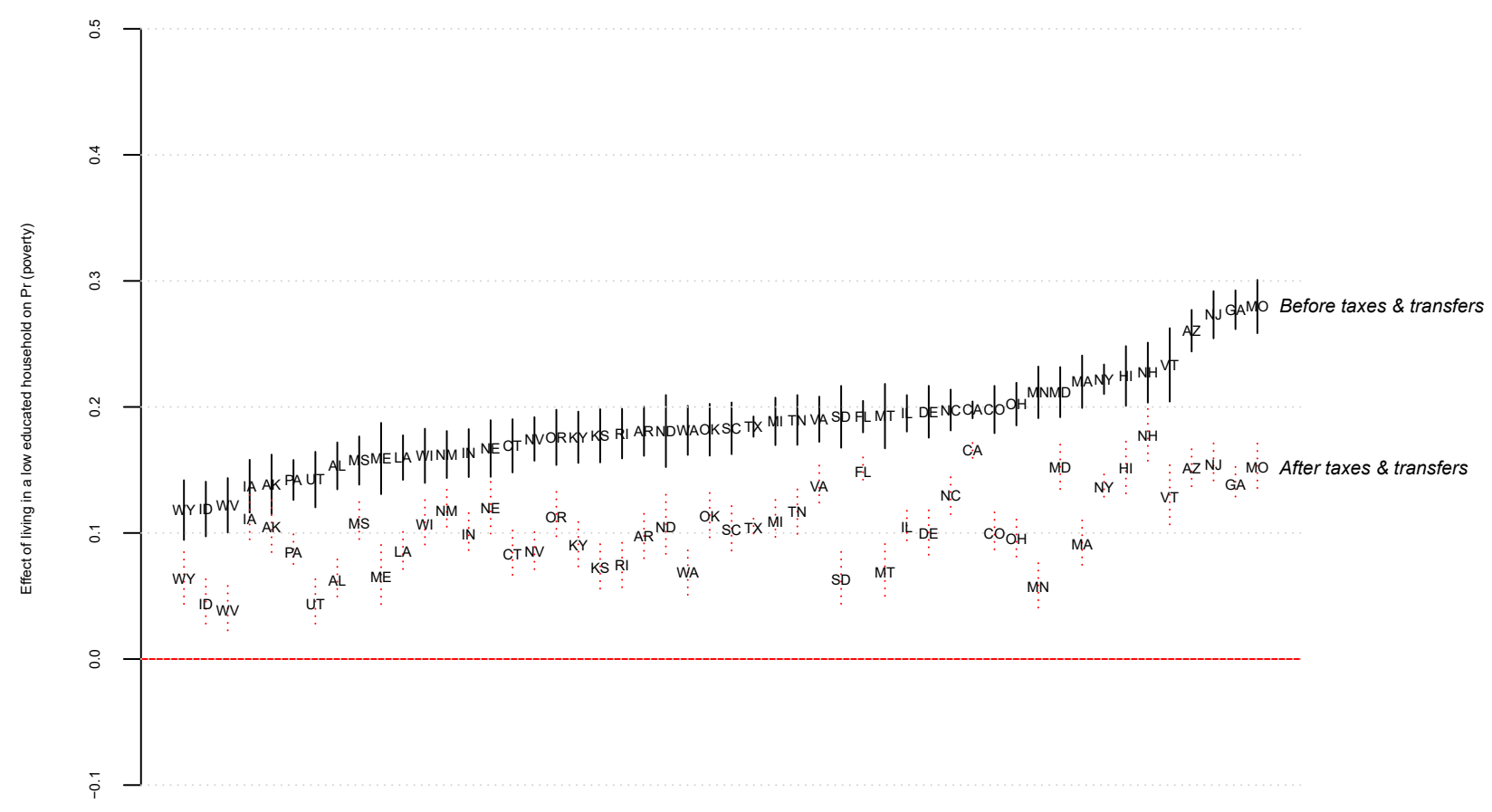

Figure 5: Low education penalty: effects of living with a less educated head on $\operatorname{Pr}$ (poverty) before and after taxes and transfers (2012-2016 CPS). Adjustments for SNAP, SSI, and TANF underreporting were made using the Urban Institute Transfer Income Model (TRIM). Effects represent coefficients from varying slope linear probability models predicting SPM poverty. The nonvarying slopes in the model are year fixed effects and a control for metropolitan and/or nonmetropolitan status. States are indicated by their postal code abbreviations. 


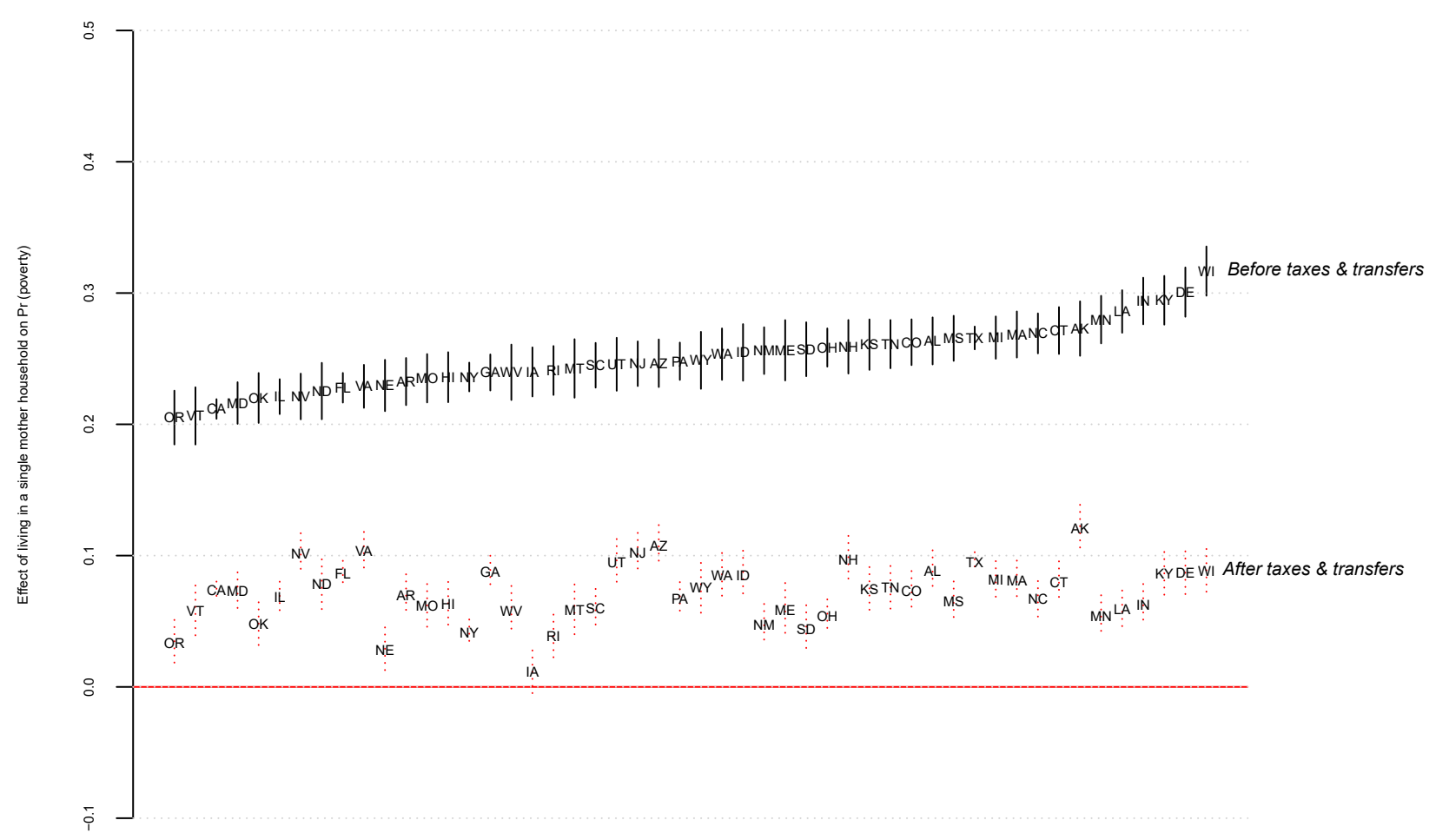

Figure 6: Single-mother penalty: effects of living in a single-mother household on Pr (poverty) before and after taxes and transfers (2012-2016 CPS). Adjustments for SNAP, SSI, and TANF underreporting were made using the Urban Institute Transfer Income Model (TRIM). Effects represent coefficients from varying slope linear probability models predicting SPM poverty. The nonvarying slopes in the model are year fixed effects and a control for metropolitan and/or nonmetropolitan status. States are indicated by their postal code abbreviations.

poverty that is associated with each risk factor after taking taxes and transfers into account. Between-state variation in the probability of living in poverty is reduced by 92 percent after taking into account taxes and transfers, the prevalence of the six risk factors, and the residual state-specific penalties associated with each of the six risk factors.

\section{The Impact of the Cost-of-Living Adjustment}

Figures A2 through A10 in the online supplement show the results in Figures 1 through 9 without adjusting the SPM thresholds for metropolitan area differences in expenses and the cost of housing. Without the cost-of-living adjustment, the rank order of states changes considerably. In particular, California is no longer a poverty outlier. Figure A2 shows that without the adjustment, poverty in California is equivalent to the national poverty rate of 13.3 percent, and Mississippi becomes the highest-poverty state at 19.5 percent. What is clear is that regardless of whether or not we adjust for cost-of-living differences, prevalences are more closely related to SPM poverty than are penalties. 


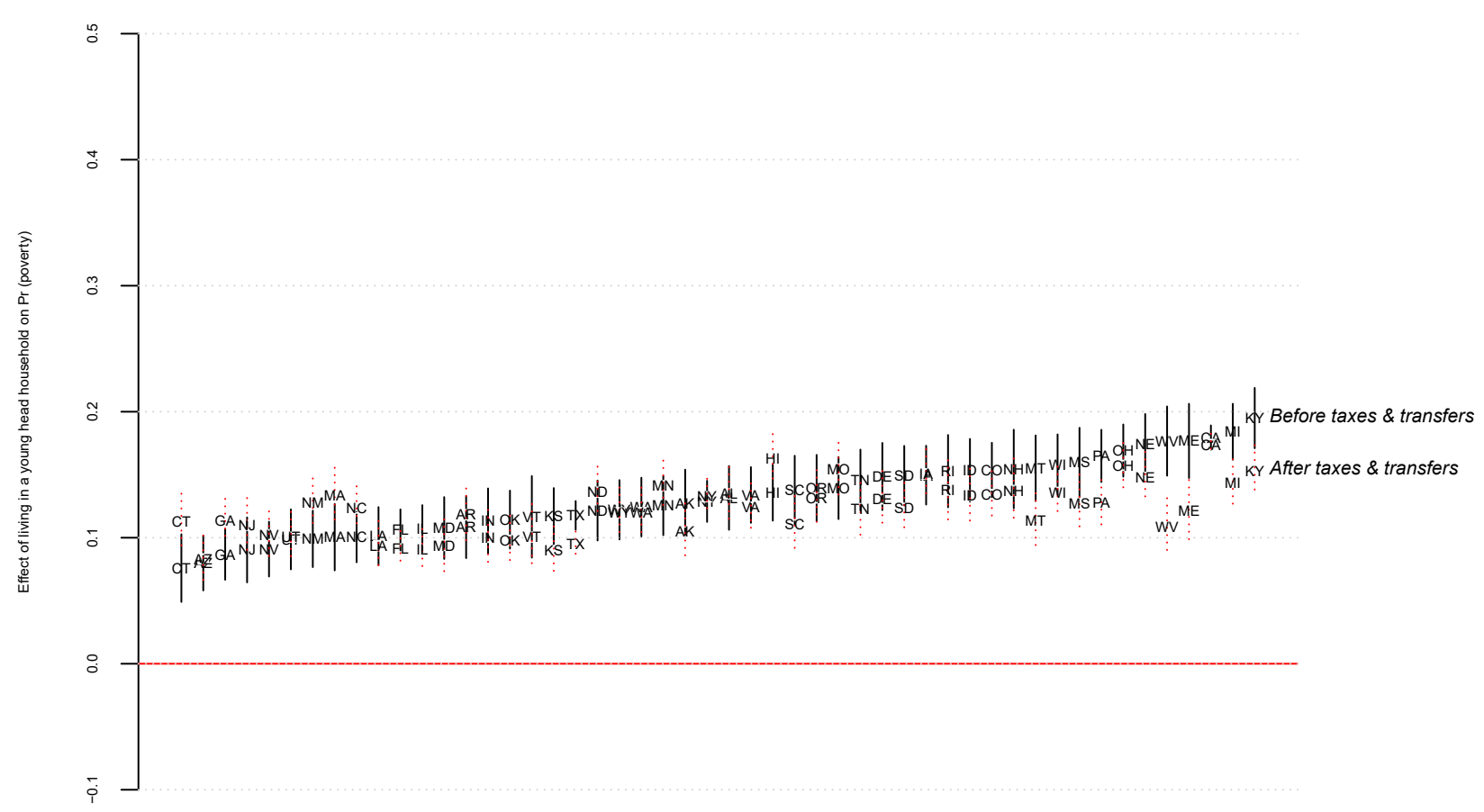

Figure 7: Young head of household penalty: effects of living with a head below age 25 on $\operatorname{Pr}$ (poverty) before and after taxes and transfers (2012-2016 CPS). Adjustments for SNAP, SSI, and TANF underreporting were made using the Urban Institute Transfer Income Model (TRIM). Effects represent coefficients from varying slope linear probability models predicting SPM poverty. The nonvarying slopes in the model are year fixed effects and a control for metropolitan and/or nonmetropolitan status. States are indicated by their postal code abbreviations.

\section{Decomposing State Poverty Differences}

In the analysis that follows, we decompose the difference in SPM poverty (after taxes and transfers) in each state versus the rest of the United States. This approach allows us to show how the relationship between prevalences, penalties, and poverty varies across states. In the online supplement, we include the results for each state. Below we present the results for four states that represent the full range of the SPM poverty distribution.

The rank order of state SPM rates in Figure 11 is California (20 percent, top-left plot), Texas (13.5 percent, top-right plot), Ohio (10.9 percent, bottom-left plot), and Iowa (7.3 percent, bottom-right plot). Each plot shows the results of decomposing the poverty differential between those who live in the given state and those who do not. The "Endowments" section of each plot represents the portion of the total difference that can be attributed to differences in prevalences. The "Coefficients" section represents the portion of the total difference that can be attributed to differences in penalties (after taxes and transfers). Bars below zero indicate factors that pull the state below the rest of the country; bars above zero represent factors that push the state above the rest of the country. Unexplained penalties are represented by the intercept for the coefficients. The $\mathrm{x}$ axis represents the percentage points that can be 


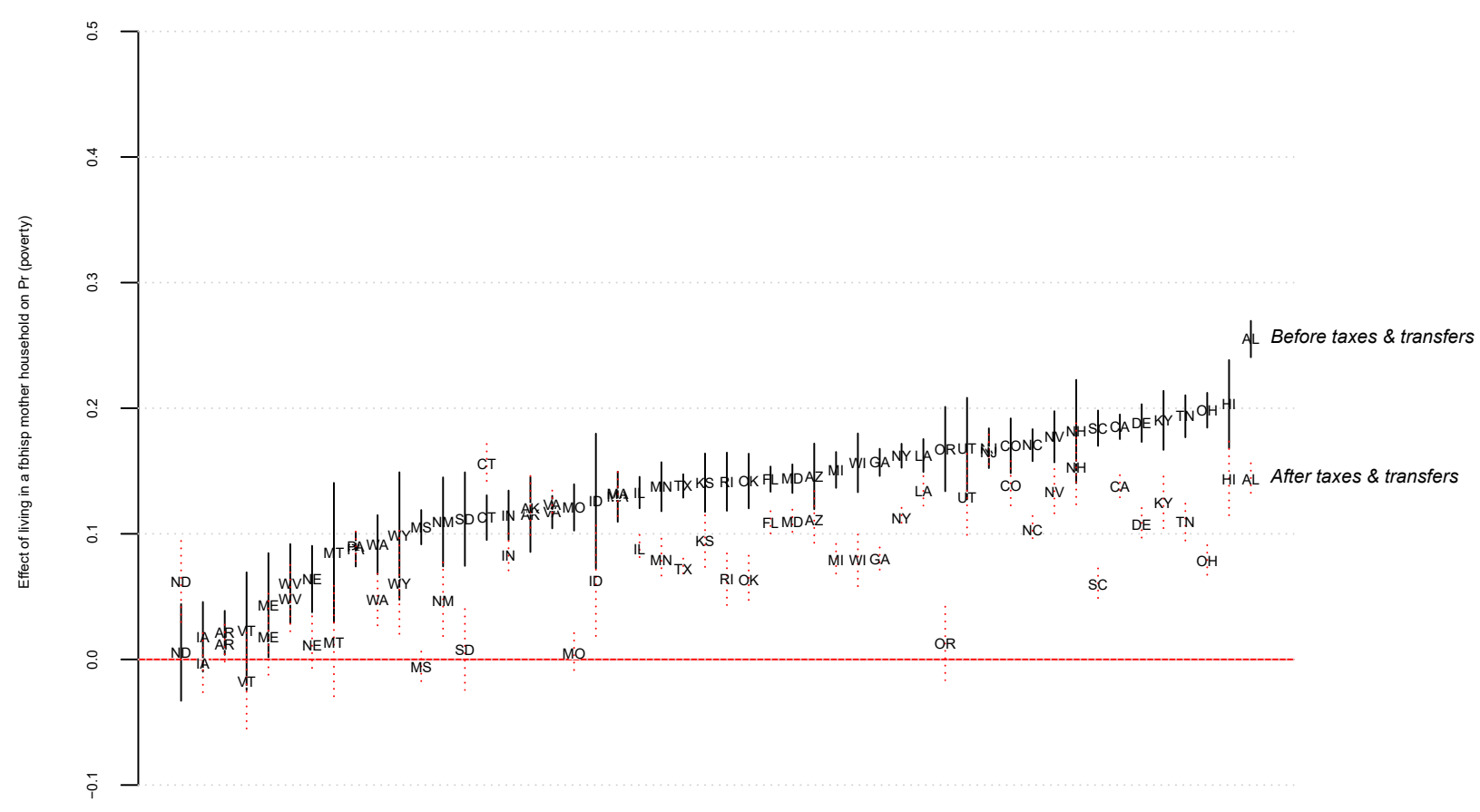

Figure 8: Foreign-born Hispanic penalty: effects of living in with a foreign-born Hispanic head on $\operatorname{Pr}$ (poverty) before and after taxes and transfers (2012-2016 CPS). Adjustments for SNAP, SSI, and TANF underreporting were made using the Urban Institute Transfer Income Model (TRIM). Effects represent coefficients from varying slope linear probability models predicting SPM poverty. The nonvarying slopes in the model are year fixed effects and a control for metropolitan and/or nonmetropolitan status. States are indicated by their postal code abbreviations.

attributed to each component. For example, of the 9 percentage point difference between the poverty probability for California versus the rest of the country, slightly more than 4 percentage points can be attributed to an unexplained penalty, 2.6 percentage points can be attributed to the high prevalence of foreign-born Hispanic households, and 1.4 percentage points can be attributed to the high prevalence of less educated households.

The results in the California plot suggest that California's high poverty rate (relative to other states) can be attributed to high prevalences and penalties associated with foreign-born Hispanic and less educated households. However, an even larger share California's high poverty rate can be attributed to unexplained penalties, one of which is California's high cost of living. In Texas, the high prevalence of Hispanic immigrants is offset by a below-average penalty. A large share of Ohio's above-average poverty level can be attributed to unexplained contextual factors. Iowa benefits from low prevalences and low penalties.

Figure 11 is just a sample of four states across the poverty distribution. Based on the decomposition results from all of the states (see the online supplement), we conclude that (1) in many states, unexplained penalties are a significant contributor to the state's deviation from the nationwide poverty rate, and (2) the contribution of prevalences and penalties to state-level poverty varies substantially across states. ${ }^{13}$ 


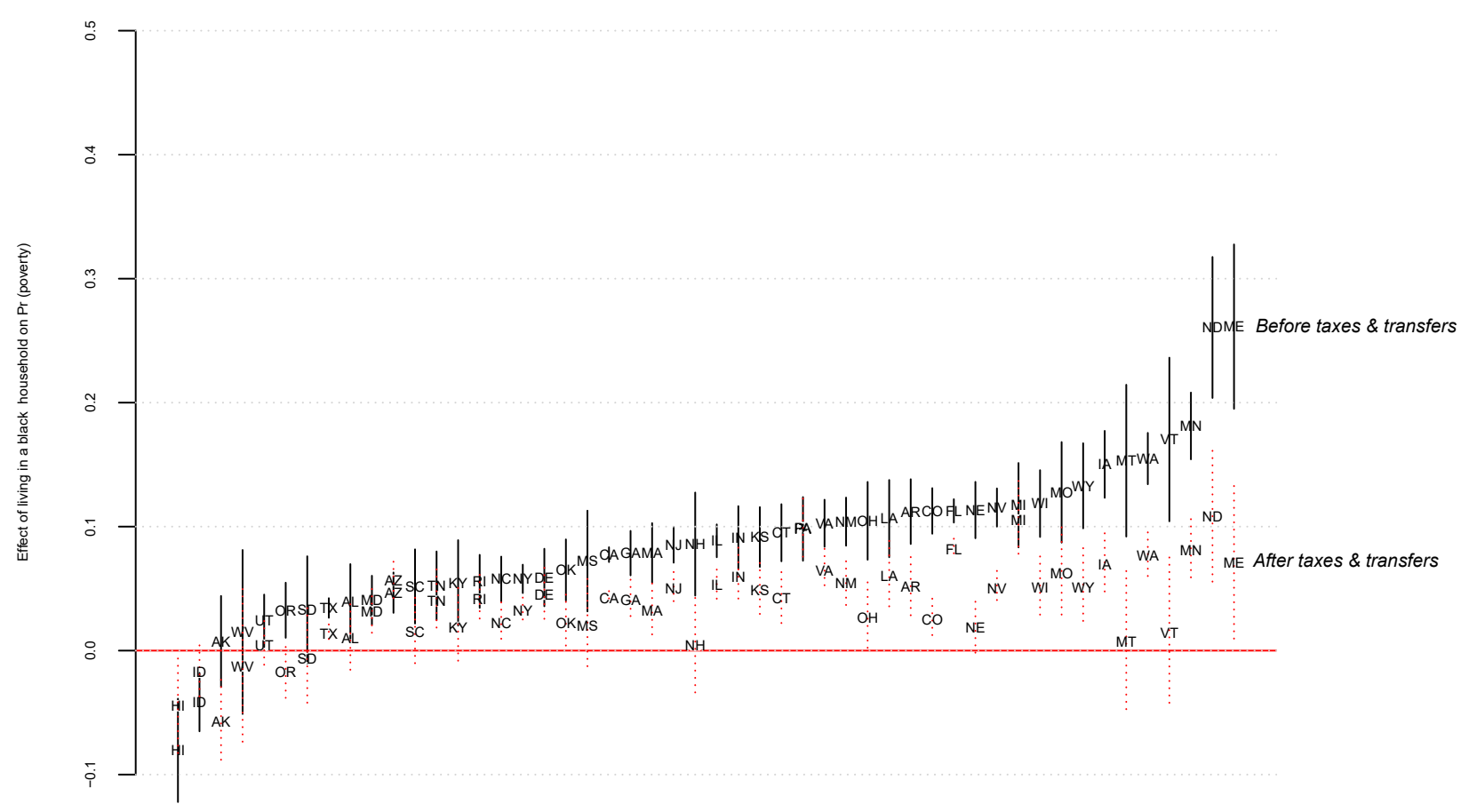

Figure 9: Black penalty: effects of living in with a black head on Pr (poverty) before and after taxes and transfers (2012-2016 CPS). Adjustments for SNAP, SSI, and TANF underreporting were made using the Urban Institute Transfer Income Model (TRIM). Effects represent coefficients from varying slope linear probability models predicting SPM poverty. The nonvarying slopes in the model are year fixed effects and a control for metropolitan and/or nonmetropolitan status. States are indicated by their postal code abbreviations.

\section{Discussion}

Our analysis demonstrates the utility of BFH's prevalence-penalty theoretical framework for understanding why state poverty rates vary so substantially in the United States. We quantify state-specific penalties associated with the four major BFH risk factors (less educated head, single mother head, young head, unemployed household), and we show the extent to which penalties are mitigated by government transfers (Figures 4-9). We agree with BFH's argument that the prevalence of single motherhood is not the primary factor driving up poverty rates, at least at the state level. This is partly because the U.S. safety net-albeit weak compared to other countries-provides more for single mothers than it does for other disadvantaged groups (Figures 4-9). Compared to single motherhood, education and employment vary more across states and have a stronger correlation with poverty.

$\mathrm{BFH}$ find that country-level differences in poverty probabilities are more closely tied to penalties than are prevalences. We find that the opposite is true for state-level differences. We do not dispute BFH's finding that poverty is high in the United States relative to other countries because of high penalties in the United States. Reducing penalties - by expanding the federal safety net, for example-would likely reduce poverty in all 50 states simply because penalties do not vary that 

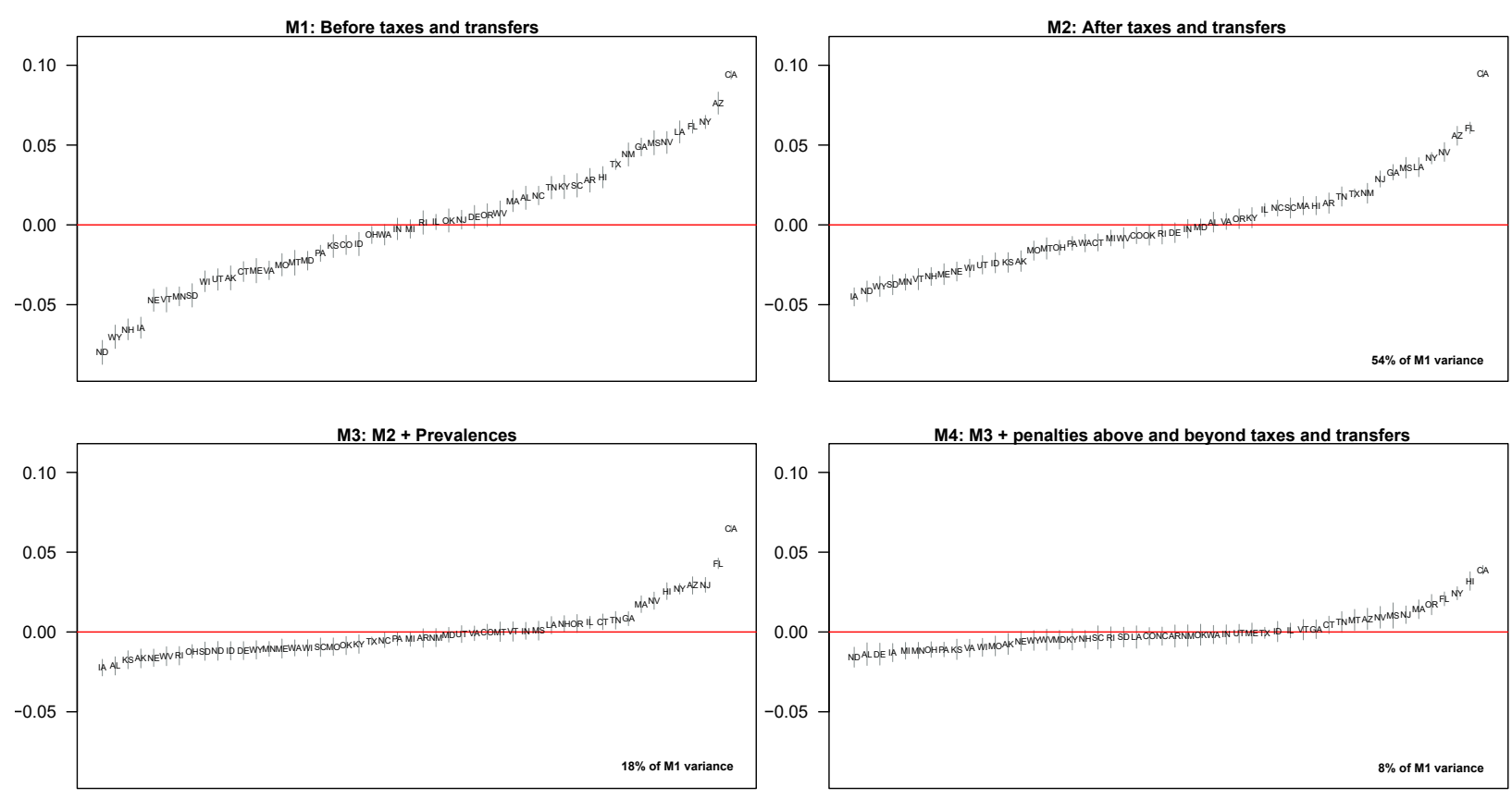

Figure 10: State random effects from hierarchical linear probability models predicting SPM poverty (20122016 CPS). States are indicated by their postal code abbreviations. Adjustments for SNAP, SSI, and TANF underreporting were made using the Urban Institute TRIM. State random effects are estimated as deviations from the overall mean (the overall mean is estimated as a weighted average of the state means). All models include a control for the number of people in a houseold, metropolitan and/or nonmetropolitan status, and year fixed effects. Vertical lines represent 95 percent confidence intervals. States are indicated by their postal code abbreviations.

much between states. In order to understand why poverty varies within the United States, risk prevalences have to be taken into consideration. We account for nearly all of the variance in state poverty probabilities (Figure 10) by controlling for the prevalence of risk factors, government transfers, and the residual state penalties associated with risk factors. We also show how geographic differences in the cost of living affect interstate differences in SPM poverty rates and probabilities (Figures A1-A10). California (the state with the highest housing costs) could cut its poverty rate by 35 percent if the cost of living in California was closer to the nationwide average (Figure A1).

As long as there are pervasive racial and ethnic disparities in access to opportunity, the effects of antipoverty policies will be unequal across racial and ethnic groups. BFH theoretically constrain poverty risk factors to only include those that are not ascriptive and are at least partially malleable. BFH's cross-national analysis excludes race and ethnicity in part because the measurement of race and ethnicity varies widely across countries. We measure the effects of two additional poverty risk factors: living with a black head of household and living with a foreign-born Hispanic head of household. The prevalence of black and Hispanic immigrant households varies substantially across states, and there is a moderately strong correlation (Figure 2) between the prevalence of the two risk factors and state poverty 

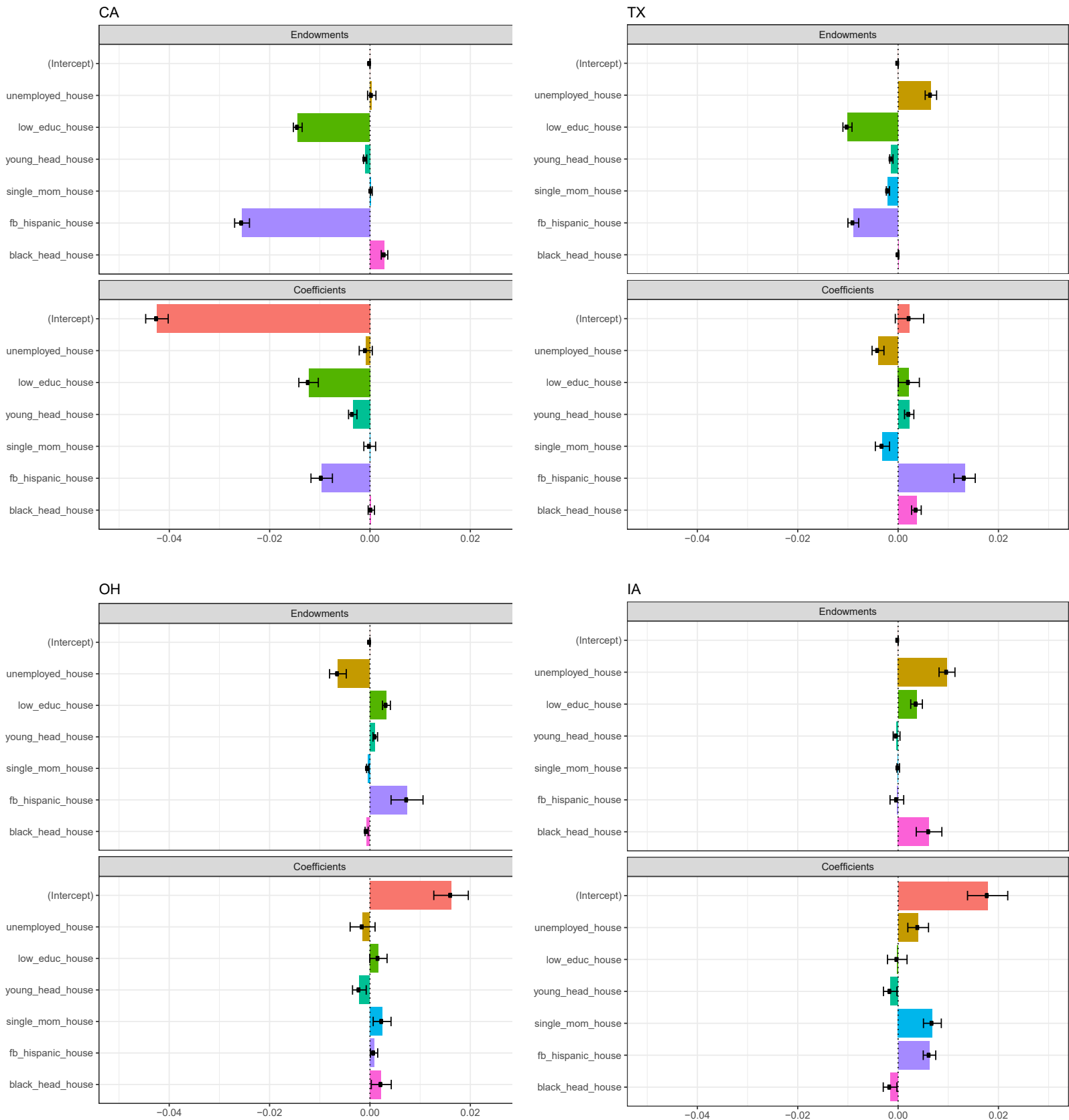

Figure 11: Decomposition of poverty differences for select states.

rates. Obviously these measures are picking up a wide range of life experiences and accumulated disadvantage that is concentrated among black and Hispanic immigrant households. Figures 8 and 9 show that in most states, the penalties experienced by these households are substantial even after controlling for race differences in education, employment, and single motherhood. 
This analysis is not without limitations. Our results may be biased depending on the role of selection and unobserved variables. A high penalty for unemployed households, for example, may reflect limited state resources for the unemployed. Or there may be unobserved factors that make the unemployed within a given state more at risk of falling into poverty. We focus on taxes and transfers, but there are many potential ways, observed and unobserved, that state context can affect economic outcomes. Moreover, these state-level factors tend to be highly correlated.

Although we find that state poverty differences are closely tied to the prevalence of high-risk populations across states, our results do not suggest that state-level antipoverty policy should be solely focused on changing behavior. Rather, given the interstate variation in our decomposition results and the large influence of the cost-of-living adjustment, we conclude that state antipoverty policy should take into account cost-of-living penalties as well as the state-specific relationship between poverty, prevalences, and penalties (observed and unobserved).

\section{Notes}

1 Throughout this study, we use the Urban Institute's Transfer Income Model (TRIM) to correct for the underreporting of transfer program benefits in the CPS.

2 Though recent evidence suggests that the TRIM slightly overimputes SNAP benefits among households with lower incomes (Stevens, Fox, and Heggeness 2018), the TRIM imputations more closely match aggregate administrative values than the unadjusted CPS ASEC. In the online supplement, we include results without the TRIM adjustments.

3 See Nolan et al. (2016) for a detailed description of the geographical adjustments and historical trends for each state.

$4 \mathrm{BFH}$ do not provide a justification for restricting the "young head" population to those under the age of 25 .

5 We considered defining a less educated household as one in which the head has a high school diploma or less (38 percent of people in our sample live in such a household). According to both the Bayesian information criterion (BIC) and the Akaike information criterion (AIC), the model with low education defined as having less than a high school diploma was a better fit than the model with low education defined as having a high school diploma or less.

6 Secondary SPM units make up less than 5 percent of SPM units. For the rare secondary units in which there are two or more people with the same oldest age in the unit, we randomly select the head among those who share the oldest age.

7 We use the lme4 package in $\mathrm{R}$ to estimate the multilevel linear probability models (Bates et al. 2015).

8 We use Hlavac's 2018 oaxaca package in $\mathrm{R}$ to estimate and plot the results from the decomposition.

9 The geographic adjustment the U.S. Census Bureau makes to the SPM poverty threshold is based on 5-year American Community Survey (ACS) estimates of median gross rents for two-bedroom units with complete kitchen and plumbing facilities. Separate medians are estimated for each of the 298 metropolitan statistical areas that are large enough to be identified on the public-use version of the CPS ASEC file. For each state, a median is estimated for all nonmetropolitan areas and for a combination of all smaller metropolitan 
areas within a state, resulting in 385 adjustment factors. See Renwick and Fox (2016) for more information about the geographical adjustments.

10 We use the tile package in $\mathrm{R}$ to make the scatterplots (Adolph 2018). We use MMestimation fit lines because they minimize residuals and are robust to outliers (Pitselis 2013).

11 In their country-level analysis, BFH find no evidence for the hypotheses that high penalties discourage prevalences or that low penalties encourage prevalences. We only find suggestive evidence of a mildly negative correlation $(-0.24)$ between penalties and prevalences across U.S. states for one risk factor: unemployment. If penalties strongly discouraged prevalences, then the correlation between penalties and prevalences should be close to -1 . The penalty-to-prevalence correlation coefficients we observe vary from a low of -0.24 (unemployment) to a high of 0.29 (black head of household).

12 See Figure A11 of the online supplement to see how California is no longer an outlier when the cost of housing it not taken into account.

13 Unexplained penalties in the decomposition models include between-state cost-of-living differences as well as unobserved state-level characteristics. The decomposition results from the data without the TRIM adjustments are in the online supplement.

\section{References}

Adolph, Christopher. 2018. Tile. Retrieved April 8, 2016 (faculty.washington.edu/ cadolph/software).

Bates, Douglas, Martin Mächler, Ben Bolker, and Steve Walker. 2015. “Fitting Linear MixedEffects Models Using lme4." Journal of Statistical Software 67:1-48. https ://doi .org/10. 18637/jss.v067.i01.

Binder, Alan S. 1973. "Wage Discrimination: Reduced Form and Structural Estimates." Journal of Human Resources 8:436-55. https://doi .org/10.2307/144855.

Bitler, Marianne, and Hilary Hoynes. 2016. "The More Things Change, the More They Stay the Same? The Safety Net and Poverty in the Great Recession." Journal of Labor Economics 34:403-44. https://doi.org/10.1086/683096.

Blank, Rebecca M., David Card, Frank Levy, and James L. Medoff. 1993. "Poverty, Income Distribution, and Growth: Are They Still Connected?" Brookings Papers on Economic Activity 1993:285-339. https://doi .org/10.2307/2534568.

Bloome, Deirdre. 2014. "Racial Inequality Trends and the Intergenerational Persistence of Income and Family Structure." American Sociological Review 79:1196-225. https://doi. org/10.1177/0003122414554947.

Brady, David. 2009. Rich Democracies, Poor People. New York, NY: Oxford University Press. https://doi.org/10.1093/acprof : oso/9780195385878.001.0001.

Brady, David, Ryan M. Finnigan, and Sabine Hübgen. 2017. "Rethinking the Risks of Poverty: A Framework for Analyzing and Comparing Prevalences and Penalties." American Journal of Sociology 123:740-86. https://doi.org/10.1086/693678.

Cellini, Stephanie Riegg, Signe-Mary McKernan, and Caroline Ratcliffe. 2008. "The Dynamics of Poverty in the United State: A Review of Data, Methods, and Findings." Journal of Policy Analysis and Management 27:577-605. https://doi .org/10.1002/pam. 20337. 
Center on Budget and Policy Priorities. 2015a. State Fact Sheets: How States Have Spent Federal and State Funds Under the TANF Block Grant. Retrieved September 13, 2018 (https://www.cbpp.org/research/family-income-support/ how-states-use-federal-and-state-funds-under-the-tanf-block-grant).

Center on Budget and Policy Priorities. 2015b. State General Assistance Programs Are Weakening Despite Increased Need. Retrieved September 13, 2018 (https://www.cbpp.org/research/family-income-support/ state-general-assistance-programs-are-weakening-despite-increased).

Center on Budget and Policy Priorities. 2018. Policy Basics: The Supplemental Nutrition Assistance Program (SNAP). Retrieved September 13, 2018 (https://www . cbpp.org/research/ policy-basics-the-supplemental-nutrition-assistance-program-snap).

Chetty, Raj, Nathaniel Hendren, Maggie R. Jones, and Sonya R. Porter. 2018. Race and Economic Opportunity in the United States: An Intergenerational Perspective. Working paper.

Cohen, Philip N. 2015. “Divergent Responses to Family Inequality.” Pp. 25-34 in Families in an Era of Increasing Inequality, edited by S. McHale, J. Van Hook, P. R. Amato, and A. Booth. New York, NY: Springer.

Currie, Janet M. 2006. The Invisible Safety Net: Protecting the Nation's Poor Children and Families. Princeton, NJ: Princeton University Press.

Dahl, Gordon B. 2010. “Early Teen Marriage and Future Poverty.” Demography 47:689-718. https://doi.org/10.1353/dem.0.0120.

Diaz, Christina J., and Jeremy E. Fiel. 2016. "The Effect(s) of Teen Pregnancy: Reconciling Theory, Methods, and Findings." Demography 53:85-116. https://doi.org/10.1007/ s13524-015-0446-6.

Edin, Kathryn, and H. Luke Shaefer. 2015. \$2 a Day: Living on Nothing in America. Boston, MA: Houghton-Mifflin Harcourt.

Flores, Stella M. 2010. "State Dream Acts: The Effect of In-State Resident Tuition Policies and Undocumented Latino Students." The Review of Higher Education 33:239-83. https : //doi.org/10.1353/rhe.0.0134.

Fox, Liana E., Misty L. Heggeness, José Pacas, and Kathryn Stevens. 2017. Precision in Measurement: Using SNAP Administrative Records to Evaluate Poverty Measurement. U.S. Census Bureau Social, Economic, and Housing Statistics Division Working Paper 2017-49.

Hahn, Heather, Laudan Y. Aron, Cary Lou, Eleanor Pratt, and Adaeze Okoli. 2017. Why Does Cash Welfare Depend on Where You Live? Retrieved September 13, 2018 (https : / www . urban. org/research/publication/why-does-cash-welfare-depend-where-you-live/ view/full_report).

Hardy, Bradley, Timothy Smeeding, and James P. Ziliak. 2018. “The Changing Safety Net for Low-Income Parents and Their Children: Structural or Cyclical Changes in Income Support Policy." Demography 55:189-221. https ://doi .org/10.1007/s13524-017-0642-7.

Harris, Kathleen Mullan. 1996. "Life after Welfare: Women, Work, and Repeat Dependency." American Sociological Review 61:407-26. https://doi.org/10.2307/2096356.

Hlavac, Marek. 2018. oaxaca: Blinder-Oaxaca Decomposition in R. R package version 0.1.4. Retrieved June 13, 2018 (https : //CRAN.R-project .org/package=oaxaca). 
Hoynes, Hilary W., and Ankur J. Patel. 2017. “Effective Policy for Reducing Poverty and Inequality? The Earned Income Tax Credit and the Distribution of Income." Journal of Human Resources, first published on July 7, 2017, as doi : 10.3368/jhr .53.4.1115.7494R1.

Kickham, Kenneth, and David A. Ford. 2009. "Are State Marriage Initiatives Having an Effect? An Initial Exploration of the Impact on Divorce and Childhood Poverty Rates." Public Administration Review 69:846-54. https://doi .org/10.1111/j.1540-6210.2009. 02034.x.

Laird, Jennifer. 2015. “Unemployment among Mexican Immigrant Men in the United States, 2003-2012." Social Science Research 49:202-16. https://doi .org/10.1016/j .ssresearch. 2014.08 .009$.

Lopez, Mark Hugo, and D'Vera Cohn. 2011. Hispanic Poverty Rate Highest in New Supplemental Census Measure. Retrieved September 13, 2018. (http://www . pewhispanic .org/2011/11/ 08/hispanic-poverty-rate-highest-in-new-supplemental-census-measure/).

McKernan, Signe-Mary, and Caroline Ratcliffe. 2005. “Events that Trigger Poverty Entries and Exits." Social Science Quarterly 86:1146-69. https://doi .org/10.1111/j .0038-4941. 2005.00340.x.

McLanahan, Sara. 2004. "Diverging Destinies: How Children Are Faring Under the Second Demographic Transition." Demography 41:607-27. https://doi .org/10.1353/dem. 2004. 0033.

Meyer, Bruce D., and Nikolas Mittag. 2015. Using Linked Survey and Administrative Data to Better Measure Income: Implications for Poverty, Program Effectiveness, and Holes in the Safety Net. National Bureau of Economic Research Working Paper 21676.

Moffitt, Robert A. 2015. “The Deserving Poor, the Family, and the U.S. Welfare System." Demography 52:729-49. https://doi .org/10.1007/s13524-015-0395-0.

Nolan, Laura, Irwin Garfinkel, Neeraj Kaushal, JaeHyun Nam, Jane Waldfogel, and Christopher Wimer. 2016. “A New Method for Measuring Historical Poverty Trends: Incorporating Geographic Differences in the Cost of Living Using the Supplemental Poverty Measure." Journal of Economic and Social Measurement 41:237-64. https ://doi .org/10. $3233 / \mathrm{JEM}-160433$.

Nolan, Laura, Christopher Wimer, Irwin Garfinkel, Neeraj Kaushal, and Jane Waldfogel. 2017. State Policy and Child Poverty: Simulating the Impact of a Race to the Top. Paper presented at the Population Association of America Annual Meeting, April 27-29, Chicago, IL. Retrieved September 13, 2018 (https://paa.confex.com/paa/2017/meetingapp.cgi/ Paper/13417).

Oaxaca, Ronald L. 1973. "Male-Female Wage Differentials in Urban Labor Markets." International Economic Review 14:693-709. https : //doi .org/10.2307/2525981.

Parolin, Zachary, and Christiaan Luigjes. 2018. Incentive to Retrench? Institutional Moral Hazard among Federal and State Social Assistance Programs after Welfare Reform. University of Antwerp Herman Deleeck Centre for Social Policy Working Paper 1802.

Perna, Laura W., Heather Rowan-Kenyon, Angela Bell, Scott L. Thomas, and Chunyan Li. 2008. "A Typology of Federal and State Programs Designed to Promote College Enrollment." The Journal of Higher Education 79:243-67. https : //doi . org/10 .1080/00221546. 2008. 11772098. 
Pitselis, Georgios. 2013. "A Review on Robust Estimators Applied to Regression Credibility." Journal of Computational and Applied Mathematics 239:231-49. https://doi .org/10.1016/ j.cam.2012.09.009.

Renwick, Trudi, and Liana Fox. 2016. The Supplemental Poverty Measure: 2015. Retrieved September 13, 2018 (https://www.census.gov/library/publications/2016/ demo/p60-258.html).

Schott, Liz, Ladonna Pavetti, and Ife Floyd. 2015. How States Use Federal and State Funds Under the TANF Block Grant. Center on Budget and Policy Priorities Technical Report. 15979. Washington, DC: Center on Budget and Policy Priorities.

Short, Kathleen. 2015. The Supplemental Poverty Measure: 2014. U.S. Census Bureau Report. P60-254. Washington, DC: U.S. Census Bureau.

Sommers, Benjamin D., and Donald Oellerich. 2013. “The Poverty-Reducing Effect of Medicaid." Journal of Health Economics 32:816-32. https : //doi . org/10.1016/j . jhealeco. 2013.06 .005 .

Stevens, Kathryn, Liana E. Fox, and Misty L. Heggeness. 2018. Precision in Measurement: Using State-Level SNAP Administrative Records and the Transfer Income Model (TRIM3) to Evaluate Poverty Measurement. U.S. Census Bureau Social, Economic, and Housing Statistics Division Working Paper 2018-15.

Urban Institute. 2018a. Public Welfare Expenditures. Retrieved March 22, 2018 (https://www.urban.org/policy-centers/cross-center-initiatives/ state-local-finance-initiative/state-and-local-backgrounders/ public-welfare-expenditures).

Urban Institute. 2018b. Welfare Rules Database. Retrieved January 18, 2018 (http://wrd. urban.org/wrd/Query/query.cfm).

Wimer, Christopher, Marybeth Mattingly, Sara Kimberlin, Caroline Danielson, and Sarah Bohn. 2015. Poverty and Deep Poverty in California. Retrieved February 7, 2018 (https://inequality.stanford.edu/sites/default/files/CPM_Brief_ Poverty-Deep-Poverty_0.pdf).

Wimer, Christopher, Marybeth Mattingly, Sara Kimberlin, Jonathan Fisher, Caroline Danielson, and Sarah Bohn. 2017. California's Poverty Rate Goes Down, But 7.5 Million Remain Poor. Retrieved February 7, 2018 (https://inequality.stanford.edu/sites/default/ files/california_poverty_measure_2015.pdf).

Yang, Zhou, and Laura M. Gaydos. 2010. "Reasons for and Challenges of Recent Increases in Teen Birth Rates: A Study of Family Planning Service Policies and Demographic Changes at the State Level." Journal of Adolescent Health 46:517-24. https ://doi .org/10.1016/j . jadohealth.2010.03.021. 
Acknowledgments: A draft of this article was presented at the 2017 meeting of the American Sociological Association. We are grateful to David Brady and Jake Rosenfeld for their insights on a prior version of this article. This research is supported by generous funding from The JPB Foundation and the Annie E. Casey Foundation.

Jennifer Laird: Department of Sociology, Lehman College.

E-mail: jennifer.laird@lehman.cuny.edu

Zachary Parolin: Herman Deleeck Centre for Social Policy, University of Antwerp. E-mail: Zachary.Parolin@uantwerpen.be

Jane Waldfogel: School of Social Work, Columbia University.

E-mail: j.waldfogel@columbia.edu

Christopher Wimer: School of Social Work, Columbia University.

E-mail: cw2727@columbia.edu. 